\title{
How Schoolchildren Choose Their Friends, How Teachers Think about These Relationships and What Influence They Have
}

\author{
Ursula Dopplinger \\ Institute of Development and Research, Christian University College of Vienna/Krems, Dr. Gschmeidlerstr. 28, 3500 Krems \\ *Corresponding Author: ursula.dopplinger@kphvie.ac.at
}

Copyright (C 2014Horizon Research Publishing All rights reserved

\begin{abstract}
This study explores the personal student attributes which influence a student being accepted by their peers and teachers, within a primary school context. The literature surrounding this construct outlines the important roles of peer groups in socialization. Being part of the relations to classmates, pupils classify each other automatically or even unknowingly into categories as a reaction of emotions and acceptance within the strict frame of reference existing in primary schools. Although human beings adopt their behavior to their perceptions, children in primary school classes have different kinds of references in school. However there is a gap in literature which leaves the implicit influence of teachers expectations unexplored. So this study aims to bridge this gap by exploring on the one hand adopted actions to the classmates' expectations and on the other hand the influence of the teachers' perceptions and observations on the students' behavior. To do this, the social network analysis (SNA) was used, as it is a valid method for exploring the social mechanism which takes place in a social system like it can be found in school classes. Therefore the study was conducted in a primary school in Austria. The results demonstrated that teachers influence unknowingly their pupils' opinion about their classmates' social network, which highlights the process of social learning.
\end{abstract}

Keywords Social Network Analyses, Peer Groups, Attributes, Teachers' perception, Primary School

\section{Introduction}

Until the 1960ies the main goal for the school system was to enhance the children's cognitive capabilities[1]. Since then the function of education and socialization has changed. It has been recognized that education has much more to do with social experiences than with cumulating knowledge[2]. Additionally the achievement of pupils is influenced by their social network and the expectations of their surrounding people. Conversely, the effect of positive relations is a rather sustainable one. Dealing with aspects of the school environment from the social-psychological perspective, a rather widespread influence on classes and consequently on pupils has been noted by Zinnecker[3]. Peer groups play important roles in socialization in school, as the group members are of the same age.

Because of a strict frame of reference in classes, pupils compete with each other but not with pupils from other schools, which becomes an even bigger issue. This concept of reference systems is already indicated by Hyman and Singer[4] and Pettigrew[5].This study points out, that pupils have two kinds of references in school: The so called internal and external reference systems. The internal reference system describes the individual capacity of pupils they have according to their achievement. The classmates are part of the external reference systems, as well as the relations to classmates.

Sociometry Moreno[6] is a widely used method to analyze these relations. (See for example Gronlund[7] and Evans[8]).It consists of displaying social relations in a square sociomatrix or in a sociogram, a plot consisting of vertices representing persons and lines indicating relations between them. Often persons are then classified into categories called sociometric status, as suggested by Coie and Dodge[9] These statements represent which kind of emotions a personarises in their peers: popular, average, controversial, neglected and rejected.

Previous research examined possible correlations between sociometric structures in school classes and childrens' characteristics like ethnicity (Braha and Rutter;Davey and Mullin; Dunstone[10-12]),physical and mental disabilities (Sabornie et al.; Kastelova and Szenteova; Torrey et al.; Moreau and Leduc[13-16]), socio-economic status (Cohen[17]), academic (Luftig and Nichols; Frederickson and Furnham; Bahar[18-20]), athletic ability (Dunn et al.[21])and aggression (Walcott et al.[22]).

Social network analysis (SNA) enhances sociometric methodologies by many graph theoretical concepts and 
statistical approaches. SNA researchers used centrality measures (Zemljic and Hlebec[23]), community analyzes (Jansson[24]), and statistical network models to investigate for example homophily, which means the question whether similar persons cluster together(Lubbers, [25])referred to the saying "Birds of a feather flock together". But also structural properties of school class networks have been used by Schaefer et al.[26].

SNA can also be used to compare different perspectives on the same network. The network resulting from asking several persons about the same relationships is called a cognitive network(Krackhardt[27]).

Casciaro[28]related the variation in perception to the personalities of respondents and Hammer[29]found that a respondent's statement about their interactions with another person is strongly influenced by this person's relations to others. However, human beings adapt their actions to their perceptions, no matter if they correspond to the actual situations. But such cognitive analyzes were rarely conducted in a scholarly environment.

\section{Initial Situation}

As teachers are in any way role models and the classmates influence each other in their vitality, social and individual encounters should be highly emphasized. In his study "The Adolescent Society" in 1961James Coleman[30]pointed out that classmates do not care about the achievement of each other. Good school marks influence the pupils' prestige in class. Since James Coleman several studies have been published concerning the informal structures in organisations and institutions influenced by peer groups. For example Helmut Fend[31]and W. Specht[32] have been researching the influence on school climate because of informal interactions between classmates.

According to parents, some of the most important aspects in school are the social surroundings of classmates and their influence on each other. Since then the research of education has included not only the achievement of pupils but also the face-to-face-interactions either between pupils or between pupils and their teachers.

Pupils are able to learn more efficiently and effectively in a positive environment, as motivation enhances and conflicts suppress the pupils' ability to learn. Referring to John Hatties[33]studies of Visible Learning and Visible Learning for Teachers, there are 150 so called "effect sizes" to improve pupils' achievements. Some of the most essential "effect sizes" are: "self-reported grades/Student expectations", "Classroom discussion", "Teacher-student relationships" and "Classroom behavioural". These effect sizes are all listed within the first 16 out of 150 . Hattie, p.251,[34]. Therefore one of the most important educational goals is to consider the social behavior of children. In short, being well trained in identifying children's social behavior will lead to a more conducive learning environment for pupils. This will not only create better opportunities for pupils to achieve higher levels in their education but also to increase their self-confidence. Teachers need to be aware of the social networks among their pupils. The presented network analysis of three primary school classes aims to point out the great advantages of identifying these social networks and their application for the education of children in the future. That is to say as this Social Network Research is able to demonstrate, that the vitality of pupils is more influenced by the estimations and perceptions of teachers among their pupils rather than their social economic background and achievements.

In this paper, a network study of friendship and undesirability conducted in three primary school classes in Lower Austria is presented. The data comes from an experiment conducted by the teachers who wanted to increase their comprehension of the positive and negative ties of their pupils. Also pupils were asked whom they liked and disliked and which of their classmates liked or disliked each other. In a second step, the authors asked the teachers to state their perspectives of friendships and unacceptance among their pupils. Furthermore, a number of personal attributes of pupils were collected.

This paper addresses questions concerning the influence of these attributes on the pupils' networks.

When asked for a definition of friendship the pupils participating in this survey stated the following: "A friend is somebody who is polite and does not scold or swear at me. I can borrow things from my friend, I will be invited to play with my friend and I will invite him or her. I have a lot of fun with my friend and when I am with a friend it is not boring". Conversely, a disliked pupil is someone who "annoys me and is nasty and sometimes aggressive". Thus, the concept of friendship and undesirability in the mind of those seven to nine year olds seems to be based mostly on feelings like "fun", "boring", and "annoying" but also on rather external, easily observable aspects like the frequency of visits and sharing of goods.

When questioned about their pupils, teachers usually focus their discussion on the pupils' academic ability, for example how they are progressing in subjects such as mathematics or German.

It is unusual for a teacher to initially discuss a child's social behavior. Friendships between pupils and especially undesirability are not commonly noticed by the teachers. When explicitly questioned about the pupils' friendships, on the one hand they think about playmates during the brakes, and on the other hand they see certain friendship patterns in line with the saying "birds of a feather flock together".

This research reflects the kind of divergence between the perspectives of own experience and observation. It can be seen that the networks observed by the pupils themselves largely differs from those reported by the teachers. Furthermore, pupils' perceptions of their own networks do not at all correspond to the way other pupils see their networks. In addition, it is shown that having certain attributes does not necessarily lead to a more favorable network position. Instead, homophily-network models are 
used to reveal the influences of attributes on the relations. The results show that pupils do not choose their friendships along the measured attributes. However, teachers seem to notice only those positive and negative relations that are in line with their expectations. When pupils are asked about the ties of their classmates, they are geared to the opinions of their teachers.

\section{Data Collection and Data Description}

The data was collected in 2012 in three primary school classes in a town of Lower Austria called Tullnwith 15, 19, and 24 pupils. All three classes were of the forth form. Each child was asked to nominate its friends and those classmates it did not like by filling in a questionnaire. Thereafter it should name friendships and unaccepted relations between classmates. Furthermore, the three teachers of the investigated classes were asked to illustrate the classes' networks of friendships and unaccepted relations from their perspectives. Ties between classes were not allowed. Thus there are 3 (classes) x 3 (perspectives) x 3 (like, dislike, or neutral) networks in total.

Additionally, actor attributes were collected: Categorical attributes

- Gender (29 boys (0), 29 girls (1))

- First language (38 German (0), 20 non-german (1))

- Religion (45 Christian (0), 13 other (1))

Ordinal or metric attributes

- Father's and mother's professions (was then classified into three categories by the teachers (1=low, 2=mid, 3=high)

- Grades in German (1.9 on average on a scale from 1 to 5 , where 1 is best) and Mathematic(1.8 on average)

- Teachers' perception of the pupils personal hygiene (1.7 on average on a scale from 1 to 5 , where 1 is best)

- Teachers' sympathy for the pupils percepted by the teacher (1.9 on average on a scale from 1 to 5 , where 1 is best)

- Teachers' perception of the willingness of parents to communicate with the teachers(1.9 on average on a scale from 1 to 5 , where 1 is best)

- Number of older and younger siblings ( 0.72 younger siblings and 1.12 older siblings on average)

- Number of friends in school (8.8 on average) and outside of school (3.7 on average)

- Body height (132 $\mathrm{cm}$ on average)

- Body weight (30.4kg on average)

- Number of balanced (54.2 on average) and unbalanced (39.7 on average) triads according to ego's view (see Section 3.0.3)

The following variables were additionally derived from the proceeding:

- Ordinal or metric attributes

- Body Mass Index (BMI; 17.2 on average)
- Classification into underweight (1), normal (2), slight overweight (3), and strong overweight (4) according to the BMI (2.3 on average)

- Ratio of balanced and unbalanced triads (1.59 on average)

SNA methods were used to analyze the relational data in combination with pupils' attributes.

\section{Methods: Social Network Analysis (SNA)}

SNA denotes a collection of descriptive and statistical analysis methods for network data. A network consists of vertices representing actors and directed or undirected lines between them indicating their relation. It can be represented as an adjacency matrix of dimension as $n * n$ wheren is the number of actors and the matrix elements "aij" are 1 if Actor $i$ sent an arc to Actor $j$ and otherwise. The network can have edge weights indicating the strength of the relationship. In this case the adjacency matrix is not binary but contains any (usually positive) real number( $\mathrm{R}$ Development Core Team[35]).

\subsection{Centrality}

Centrality analyses aim to find the most important actors based on their networking behavior. Each centrality measure is associated with a different concept of importance. The focal actor is called ego and all the other network members are called alters. The centrality measures reviewed here are based on Freeman [36,37]. The Degree of Actor i (ego) is the number of its adjacent vertices. This corresponds to the row (or column) sums of A if A is undirected (symmetric).

In a directed graph, the outdegree(D-Out) refers to the number of vertices to which Actor $i$ sends an arc. Accordingly, the indegree(D-In) denotes the number of arcs send to i. The undirected degree can be thought of as an activity measure. The indegree measures popularity and the outdegree is interpreted as expansiveness.

\subsection{Closeness}

Closeness is a generalization of degree in the sense that it does not only take the direct neighbors into account but also the neighbors of neighbors and so on. Thereby an alter j's contribution to its closeness decreases as the distance between $i$ and $j$ increases. The distance between $i$ and $j(d(i ; j))$ is the minimum numbers of edges necessary to go from $i$ to $j$ (length of the shortest path). The vertex having the smallest average distance to all the other nodes is the one with the highest closeness. Thus, closeness is interpreted as a measure of reach ability[38].

The most central vertex according to closeness has the best access to information circulating in the network and it has the best possibilities to spread information. 


\subsection{Betweenness}

Betweenness is a measure to find brokers as it is defined as the ratio of the number of shortest paths going through $i$ (gjk(i)) and the overall number of shortest paths gjk, where $\mathrm{j}$ and $\mathrm{k}$ are alters. For directed networks there is no in- or outbetweenness, but only adirected betweenness differing from the undirected version in terms of definition of shortest paths. For an actor having a high betweenness, there is a large number of other vertices that can only communicate via this actor[39].

\subsection{Balance Theory}

In SNA Heider[40] defined a signed network as a network with positive and negative relations. The situation of a subgroup with three members (triad) can be derived from the signs ("+1 or $-1 ")$ that connect them. The signs occurring in the triad are multiplied, where nonexisting ties have "+1". If the product is positive which is the case with the combinations $(1,1,1)$ and $(1,-1,-1)$, the situation is called balanced because either everyone likes everyone or two actors agree on disliking the third. If the product is negative as in the cases $(-1,-1,-1)$ or $(1,1,-1)$, there are tensions, because either every actor dislikes the other two or one actor likes the other two but they do not like each other. Consequently the group of three is unable to do something together.

The extent to which someone is confronted with unbalanced network constellations corresponds to his or her exposure to uncomfortable situations. Though, an uncomfortable situation does not have to be a negative one, because the actor who is able to transform it, will receive the most esteem or the actor having positive ties in an unbalanced network can possibly benefit from the fight of the other two. Thus, an unbalanced situation can simply be described as more challenging than a balanced constellation.

\section{Results}

Three kinds of SNA were performed aiming to capture the different perspectives on the networks: Similarity analysis and centrality analysis(Section 4.1), in order to show the amount of difference between self-perspectives (SELF), classmate perspectives (THIRD) and TEACHER perspectives as well as the influence of actor attributes on tie formation (Sections 4.2 and 4.3).

\subsection{Different Perspectives on the Same Networks: SELF, THIRD, and TEACHER.}

In order to capture the similarity of networks reported by the three different groups of persons, the networks were compared according to their density and similarity.

The densities of all the networks and perspectives are listed in Table 1. The SELF sympathy networks are denser than the THIRD sympathy networks in all classes while the reverse is true for the undesirability networks. This indicates that in their self-description, pupils see more dense sympathy-networks for themselves than when described by their mates, this difference being even higher when compared to the density estimated by teachers. For the undesirability-networks, we see a different pattern: mates (THIRD) see the undesirability-networks much more dense than pupils themselves (SELF), but teachers see almost no density there. This could be an indication for a harmonizing tendency: Pupils see more sympathies for themselves than their mates see for them, and they see less disliked relations for themselves than their mates see for them. Teachers report extremely low densities in the undesirability networks, which might mean that they perceive (perhaps: want to perceive) only a small proportion of antagonism in school class.

Table 1.Densities according to different perspectives

\begin{tabular}{|c|c|c|c|c|c|c|}
\hline \multirow{2}{*}{} & \multicolumn{2}{|c|}{ Class 1 } & \multicolumn{2}{c|}{ Class 2 } & \multicolumn{2}{c|}{ Class 3 } \\
\cline { 2 - 7 } & Like & Dislike & Like & Dislike & Like & Dislike \\
\hline SELF & 0.53 & 0.36 & 0.31 & 0.24 & 0.33 & 0.40 \\
\hline THIRD & 0.29 & 0.52 & 0.27 & 0.32 & 0.26 & 0.43 \\
\hline TEACHER & 0.22 & 0.08 & 0.08 & 0.06 & 0.07 & 0.05 \\
\hline
\end{tabular}

However, the density only shows the number of ties and neglects the similarity of networks from different perspectives.

To point out an example: A correlation of -0.1 between Centrality Analysis and female gender attribute tells us that girls are slightly less central than boys in the SELF-perspective. The strongest association between centrality and attributes can be observed for non-Germanfirst language in the SELF friendship network $(-0.37)$. This indicates that pupils with non-Germanfirst language are less integrated in friendship networks than German speaking children. The second largest association can be seen between centrality in the undesirability-networks from the THIRD perspective and non-Christian religion (0.36). This tells us that pupils believe that classmates with non-Christian religion have slightly more negative relations. The correlation of -0.27 between centrality in the SELF sympathy network and religion suggests that children tend to see a similar relationship in their own networks. The relatively high correlations between centrality in the TEACHER undesirability-networks (i.e. networks of undesirability among pupils, as rated by teachers) and the grades in German (-0.32) and Mathematic (-0.22) show that teachers tend to think that pupils with low grades have slightly less negative relations: the worse the performance, the lesser enemies. Those pupils, who are performing not so well, do not have many friends. (the respective correlations in the TEACHER sympathy-networks are around 0 ). Altogether the academic abilities do not seem to have much importance from the pupil's perspectives, where the highest 
absolute correlation is 0.12 .

A moderate influence on centrality can be noted by looking at the number of balanced and unbalanced triads (capture 4, section 4.4.): Pupils who have more balanced triads tend to think that they have more friendships (correlation of 0.29 ), while children with more unbalanced triads have less positive relations (correlation of -0.26).

However, none of the correlations can be considered to be notably high (Correlations below 0,27 are non-significant on the $5 \%$-level). We conclude that the measured actor attributes have no or only marginal influence on centrality. This can lead to the hypothesis that even when attributes do not affect centrality ("How many connections does a pupil have?"; the quantitative aspect), they might still be decisive for friendship and undesirability clusters ("Whom is a pupil connected with?"; the qualitative aspect).

\subsection{The Importance of Actor Attributes for the Network Structure}

Most of the SELF reported networks, especially sympathy and neutral relations, are partly non-significant, partly inconsistent, i.e. showing in different directions in different classes. This suggests that the tie choices of pupils are hardly at all influenced by the attributes, which are pointed out below. Only the SELF reported undesirability indicates that actor attributes are important when developing negative relations: Apparently, visible attributes of other pupils make no difference for the decision of being friends. But they seem to be a useful instrument for negative relations.

To listen these attributes, there are on the one hand these metric variables like social economic status of the mother, social economic status of the father, grades German, grades Math's, personal hygiene, sympathy, parents' willingness of communication, number of siblings, number of school friends, number of other friends, body height, body weight, number of unbalanced triads, number of balanced triads, BMI, and ratio balanced/unbalanced triads. On the other hand there are the categorical variables like gender, first language and religion

Most of the parameters of the TEACHER models are consistent, high and significant. Teachers seem to be able to give quite precise prognoses on their pupils who are supposed to be connected depending on their attributes. But how much do these prognoses coincide with the pupils' views? Not much with one exception: The THIRD sympathy-network shows that pupils believe that friendship choices of their classmates depend on the attributes which their teachers think to be important. Again, this leads to a hypothesis: pupils at the age of 8-9 are much more concentrated on their own network than on the others', and therefore they might unconsciously echo the teachers' opinions when asked for their ratings on who likes whom. Unlike the SELF-networks, however, attributes are important for undesirability and unimportant for sympathy, in the THIRD-networks, it is the other way round: in this study they are unimportant for the undesirability network and important for the sympathy network.

The following pattern can be found:

Attributes of pupils are:

- SELF sympathy-network:

What pupils say about to whom they like is unimportant.

- SELF undesirability-network:

What pupils say about to whom they don't like is important

- THIRD sympathy-network:

What pupils say about to whom the others like is important

- THIRD undesirability-network:

What pupils say about to whom the others don't like is unimportant

- TEACHERs sympathy-network:

What teachers say about whom the pupils like is important

- TEACHERS undesirability-network:

What teachers say about whom pupils don't like is important

\section{Discussions}

The results show that pupils do not seem to care much about social, cognitive, cultural, or physical attributes when choosing their own friends. Teachers, on the other hand, clearly perceive friendships along those attributes. Pupils, when asked about the network of their classmates, as opposed to their own, surprisingly use pretty much the same criteria as the teachers. This result suggests at least two hypotheses. First: when observations of others' networks are requested, stereotypes are used. This is true for teachers just as much as for pupils. And these stereotypes lead many people to believe that friendships are organized along attributes, i.e. people "fitting together" by some observable criteria. These stereotypes, however, are not valid when exploring the personal perspective: pupils do not actually select their friends according to criteria of similarity, although they tend to believe that other people do. Second: The fact that pupils, when describing the networks of their mates tend to use the same criteria as their teachers, could also shed some light on the process of social learning: pupils might - more or less consciously - give more weight to the perception of teachers than to their own, when it comes to describing other pupils' networks.

\section{Conclusions}

The way teachers judge their pupils' network in school differs from the pupils' perception of the network of their classmates as well as from their opinions on their own networks. The consensus shown in section 4.1 is only $9.8 \%$ on average. Teachers realize only very few ties among their pupils and a large part of them are seen differently by the pupils themselves.

However, the three perspectives correspond when it comes to the question whether social, cultural, physical, and cognitive attributes correlate with centrality: High correlations could not be found in any of the networks. In the 
networks reported by the pupils, a moderate influence of the cultural background and balanced/unbalanced triads could be found. In contrast, teachers think that pupils with low academic abilities have slightly less negative relations.

Even though pupils' attributes do not influence centrality they lead to clustering - at least from some perspectives: Pupils do not choose their relations according to those attributes. However, attributes are important for the pupils' perceptions of their classmates' friendships as well as for the teachers' perspectives. This supports the hypothesis that pupils as well as teachers make use of stereotypes when observing the networks of others. Furthermore, the results may lead to the conclusion that pupils tend to align their opinions about the others' social ties to the teachers' perceptions. As the radius of attention of primary school children does not go far beyond their own relations, they unconsciously adopt the viewpoints of teachers when asked for their opinions. This sheds light on the process of social learning: The vacuum in the ability to judge, arising from a lack of attention, is filled by borrowing the teachers' opinions.

Among the pedagogical consequences which we might draw from our results, "knowing that we know nothing" could be the first one. If we acknowledge the fact that teachers have a quite different view on their pupils' relationships than the children themselves have, we will realize a need to be more attentive. When ever offered help in a conflict situation does not work out, this might be a result of the fact that the social relations of the pupils are not sufficiently known by the teacher. To find out about these social relations, it does not seem to be sufficient to group pupils along certain criteria of similarity, because similarity is not what they choose as a criterion. Social network analysis might help to shed light on a pupils' subjective view which determines his/her social integration.

\section{REFERENCES}

[1] H.Engelbrecht.Geschichte des österreichischen Bildungswesens,Band 4. Wien: ÖBV, 1986

[2] H.Engelbrecht.Geschichte des österreichischen Bildungswesens, Band 5. Wien: ÖBV, 1988

[3] J. Zinnecker. Die Schule als Hinterbühne oder Nachrichten aus dem Unterleben von Schülern. Stadtkids. Kinderleben zwischen Straße und Schule. Juventa Verlag, 2001.

[4] H. Hyman, E. Singer. Readings in reference group theory and research. The Free Press, 1968.

[5] T. Pettigrew. Social evaluation theory: Convergences and applications. In Nebraska Symposium on Motivation, Vol. 15, $241-311$. University of Nebraska Press, 1967.

[6] J. Moreno. Who shall survive? Foundations of sociometry, group psychotherapy, and sociodrama. Nervous and Mental Disease Publishing Co., 1934.
[7] K. Evans.Sociometry in School - 2. Applications. Educational Research, Vol. 6, No 2, 121 - 128, 1964.

[8] N. Gronlund, Sociometry in the Classroom. Harper \& Row, 1959.

[9] J. Coie, K. Dodge. Multiple sources of data on social behaviour and social status in the school: A cross-age comparison. Child Development, Vol. 59 No. 3, 1988.

[10] V. Braha, D. Rutter. Friendship choice in a mixed primary school. Educational Studies, Vol. 6: 217 - 223, 1980.

[11] A. Davey, P. Mullin. Inter-ethnic friendship in British primary schools. Educational Research, Vol. 24:83 - 92, 1982.

[12] S.Dunstone, A. Zea. Sociometric assessment of social integration of students from culturally diverse backgrounds at a nonresidential university. Journal of Group Psychotherapy, Psychodrama \&Sociometry, Vol. 47, No. 4:165 - 176, 1995.

[13] E.Sabornie, K. Marshall, E. Ellis. Restructuring of mainstream sociometry with learning disabled and nonhandicapped students. Exceptional Children, Vol. 56, No 4:314 - 323, 1990.

[14] D. Kastelova, I. Szenteova. Sociometric status of speech disordered child in the basic school class. Psychologia a PatopsychologiaDietata, Vol. 26, No 1:29-34, 1991.

[15] G.Torrey, S. Vasa, J. Maag, J. Kramer. Social skills interventions across school settings: Case study reviews of students with mild disabilities. Psychology in the Schools, Vol. 29, No 3:248 - 255, 1992.

[16] C. Moreau, A. Leduc. The effectiveness of a social skills training program for a student with mental retardation. ComportementHumain, Vol. 7, No 2:99 - 116, 1993.

[17] J. Cohen. Socio-economic status and high-school friendship choice: Elmtown's youth revisited. Social Networks, Vol. 2, No 1:65 - 74, 1979/80.

[18] R. Luftig, M. Nichols. Assessing the social status of gifted students by their age peers. Gifted Child Quarterly, Vol. 34, No 3:111 - 115, 1990 .

[19] N. Frederickson, A. Furnham. The long-term stability of sociometric status classifcation: A longitudinal study of included pupils who have moderate learning diffculties and their mainstream peers. Journal of Child Psychology and Psychiatry, Vol. 42, No 5:581 - 592, 2001.

[20] H. Bahar. The effects of gender, perceived social support and sociometric status on academic success. In Procedia Social and Behavioral Sciences, WCES-2010, No 2: 3801 - 3805, 2010 .

[21] J.C. Dunn, J.G. Dunn, A. Bayduza. Perceived athletic competence, sociometric status, and loneliness in elementary school children. Journal of Sport Behavior, Vol. 30, No 3:249 $-269,2007$.

[22] C.Walcott, A. Upton, L. Bolen, M. Brown. Associations between peer-perceived status and aggression in young adolescents. Vol. 45, No 6:550 - 561, 2008.

[23] B. Zemljic, V. Hlebec. Reliability of measures of centrality and prominence. Social Networks, Vol. 27:73 - 88, 2005.

[24] I. Jansson. Clique structure in school class data. Social 
Networks, No 19:285 - 301, 1997.

[25] M. Lubbers. Group composition and network structure in school classes: A multilevel application of the $\mathrm{p}^{*}$ model. Social Networks, Vol. 25, No 4:309 - 332, 2003.

[26] D.Schaefer, J. Light, R. Fabes, L. Hanish, C Martin. Fundamental principles of network formation among preschool children. Social Networks, Vol. 32, No 1:61 - 71, 2010.

[27] D. Krackhardt. Cognitive social structures. Social Networks, Vol. 9:109 - 134, 1987.

[28] T. Casciaro. Seeing things clearly: Social structure, personality, and accuracy in social network perception. Social Networks, Vol. 20:331 - 351, 1998.

[29] M. Hammer. Implications of behavioral and cognitive reciprocity in social network data. Social Networks, Vol. $7: 189-201,1985$.

[30] J. Coleman. The Adolescent Society. The social life of the teenager and its impact on education. Free Press, 1961.

[31] H. Fend. Sozialisation durch Literatur (Soziologie der Schule IV). Beltz, 1979.
[32] W. Specht. Altersgruppe. Informelle soziale Einussprozesse in der Schule. Konstanz, 1978.

[33] J. Hattie. Visible Learning,Routledge, New York, 2009

[34] J. Hattie. Visible Learning for Teachers. Maximizing Impact on Learning, Routledge, New York, 2012.

[35] R Development Core Team. R: A language and environment for statistical computing. $\mathrm{R}$ Foundation for Statistical Computing, Vienna, Austria, 2011.

[36] L. Freeman. Centrality in social networks: Conceptual clarifcation. Social Networks, Vol. 1: 215 - 239, 1979.

[37] L. Freeman. The development of social network analysis: A study in the sociology of science. Empirical Press, 2004.

[38] P. J.Carrington,J. Scott, S.Wasserman.Models and Methods in Social Network Analysis. Cambridge University Press, 2005.

[39] C.Prell.Social Network Analysis: History, Theory and Methodology. SAGE. 2012.

[40] F. Heider. The Psychology of Interpersonal Relations. John Wiley \& Sons, Inc., New York, 1958. 